\title{
Influência antrópica na qualidade da água da bacia hidrográfica do rio São Miguel, carste do alto São Francisco, Minas Gerais
}

\author{
Eduardo Abjaud Haddad* \\ Antônio Pereira Magalhães Júnior ${ }^{*}$
}

\section{Resumo}

A qualidade da água é um dos elementos potencialmente indicadores das atividades humanas em uma bacia hidrográfica. Este trabalho foi baseado em análises de qualidade da água da bacia do rio São Miguel, localizada na área cárstica do alto São Francisco. Mensalmente, durante um ano, foram monitorados 13 parâmetros de qualidade de água em 5 locais no rio São Miguel. Aqueles que apresentaram influências de atividades antrópicas foram analisados espacial e temporalmente. $O$ fator de poluição mais evidente é o lançamento de esgotos da ocupação urbana, responsável pela contaminação microbiológica, e ocorrência de esquistossomose no trecho do médio curso do rio. Os efeitos de atividades agropecuárias se evidenciaram no período das chuvas em função da erosão do solo nos trechos do alto e baixo curso do rio. O impacto da principal atividade econômica regional, a mineração de calcário, não se refletiu com clareza na qualidade da água.

Palavras-chave: Qualidade da água; Poluição hídrica; Carste.

\footnotetext{
Mestre em Geografia - Instituto de Geociências (IGC/UFMG) (haddadedu@yahoo.com.br).

** Prof. Departamento de Geografia Instituto de Geociências (IGC/UFMG) (magalhãesufmg@yahoo.com.br).
}

Geosul, Florianópolis, v. 25, n. 49, p 79-102, jan./jun. 2010 
HADDAD, E.A. e MAGALHÃES JR., A.P. Influência antrópica na qualidade...

Human influences on water quality of São Miguel river watershed, upper São Francisco karst, Minas Gerais

\begin{abstract}
The water quality is one of the elements that can potentially indicate human activities in watersheds. This study was based in water analysis conducted at São Miguel river basin, located in karstic terrain in Upper São Francisco basin. Monthly, during a year, samples were collected at 5 gauge stations in São Miguel river to monitoring 13 water quality variables. Those, which had demonstrated human influences, were studied spatially and temporally. Sewage discharge from urban area, although its relatively small size, was the main factor of water pollution in the river, being responsible for microbiological contamination, resulting in waterborne disease cases - schistosomosis was reported at the middle sector of the river. The effects of rural activities in water quality decay were evidenced at rainy season due soil erosion at, both in the up and low river course. The variables analyzed did not indicate clearly effects of limestone mining in the water quality, nonetheless it represents the major economic activity at the region.
\end{abstract}

Key words: Water quality; Water pollution; Karst.

\title{
Introdução
}

O estudo da influência de atividades humanas na qualidade da água demanda a consideração que corpos hídricos têm capacidade de refletir alterações de seu estado devido ao desenvolvimento de atividades antrópicas. A água é um fator na produção do espaço geográfico que condiciona a localização e a dinâmica de atividades humanas (MAGALHÃES Jr, 2003), e como efeito, estas podem implicar na sua degradação qualitativa e redução da disponibilidade hídrica, resultando no comprometimento do seu uso para finalidades diversas (LAMB, 1985). Deve-se considerar ainda que influências 
HADDAD, E.A. e MAGALHÃES JR., A.P. Influência antrópica na qualidade...

antrópicas sobre a qualidade da água estão fortemente associadas ao crescimento da urbanização, da expansão das atividades agropecuárias e industriais, que engendram alterações deletérias crescentes sobre a qualidade das águas (WORLD HEALTH ORGANIZATION - WHO, 1993; MEYBECK \& HELMER, 1996). O conhecimento do estado das águas permite auxiliar na definição de usos pretendidos, avaliar sua qualidade e indicar quais atividades humanas causam ou podem causar sua degradação. A pesquisa sobre qualidade das águas exige a definição de sua dimensão espacial. Uma delas pode ser dada pela delimitação de uma bacia hidrográfica, unidade espacial facilitadora do estudo de relações ambientais de causa-efeito (BOURLON \& BERTHON, 1998; BOTELHO \& SILVA, 2004), e preconizada como unidade territorial preferencial de gestão dos recursos hídricos pela atual Lei das Águas, $n^{\circ}$ 9.433/97 (BRASIL, 1997).

A bacia hidrográfica do rio São Miguel apresenta-se como um "cenário" potencialmente rico para o estudo dos impactos humanos sobre o ambiente. $\mathrm{O}$ rio situa-se na margem direita da bacia do Alto São Francisco, no sudoeste de Minas Gerais, e sua bacia hidrográfica insere-se numa região cárstica, onde os usos do solo abrangem campos de pastagens para pecuária, agricultura, ocupação urbana, mineração e beneficiamento de rochas carbonáticas. Estas atividades antrópicas implicam em fortes pressões sobre o frágil quadro natural da área, inclusive as águas. O objetivo geral da pesquisa é investigar os reflexos destas atividades antrópicas sobre a qualidade das águas superficiais da bacia hidrográfica do rio São Miguel.

\section{Metodologia}

O levantamento de informações preliminares envolveu os dados de pluviometria da estação Arcos de código 02045010, adquiridos junto à COMPANHIA DE PESQUISAS E RECURSOS MINERAIS - CPRM ${ }^{1}$ e os dados de qualidade da água da estação

${ }^{1}$ No prelo. 
HADDAD, E.A. e MAGALHÃES JR., A.P. Influência antrópica na qualidade...

Calciolândia de código SF-002-A, localizada no rio São Miguel (INSTITUTO MINEIRO DE GESTÃO DAS ÁGUAS - IGAM, 2005). Foi utilizado o mapa de uso e ocupação do solo da bacia hidrográfica do rio São Miguel elaborado por CHEREM (2006).

$\mathrm{O}$ monitoramento das águas superficiais foi realizado em 5 pontos de coleta ao longo do curso principal do rio São Miguel, coletor principal da bacia (FIGURA 1). Os parâmetros analisados foram 13 no total, sendo o oxigênio dissolvido - OD, $\mathrm{pH}$, temperatura da água, turbidez e condutividade elétrica medidos in situ com aparelhos portáteis. Os parâmetros coliformes termotolerantes - CT, demanda bioquímica de oxigênio - DBO, demanda química de oxigênio - DQO, nitrato - $\mathrm{N}$, fósforo total $\mathrm{PT}$, cádmio - $\mathrm{Cd}$, zinco $-\mathrm{Zn}$ e chumbo - $\mathrm{Pb}$ foram analisados no laboratório do Centro Tecnológico de Minas Gerais - CETEC, em Belo Horizonte. A periodicidade das análises foi mensal e consecutiva, durante um ano hidrológico, com início em abril de 2005 e término em março de 2006 . Foram calculadas as vazões fluviais por meio da medição de velocidades (via flutuadores) e calculo das seções do canal. Os mesmos parâmetros foram analisados de amostras coletadas em duas campanhas de campo em três nascentes, resultados que serviram como referência à condição de qualidade "natural" das águas na bacia (background).

Os resultados foram avaliados com a utilização de estatística de medida central (média aritmética, geométrica e mediana) dos parâmetros que sofreram influências antrópicas.

\section{Área de estudo}

A bacia do rio São Miguel situa-se a sudoeste de Minas Gerais, na região do Alto São Francisco (FIGURA 1). A área de drenagem perfaz aproximadamente $525 \mathrm{~km}^{2}$ e abrange, na sua maioria, parte dos municípios de Pains e Arcos. Apesar de situado em área cárstica, o rio São Miguel tem a maior parte de seu curso em superfície, e possui cerca de $40 \mathrm{~km}$ de extensão. 
HADDAD, E.A. e MAGALHÃES JR., A.P. Influência antrópica na qualidade...

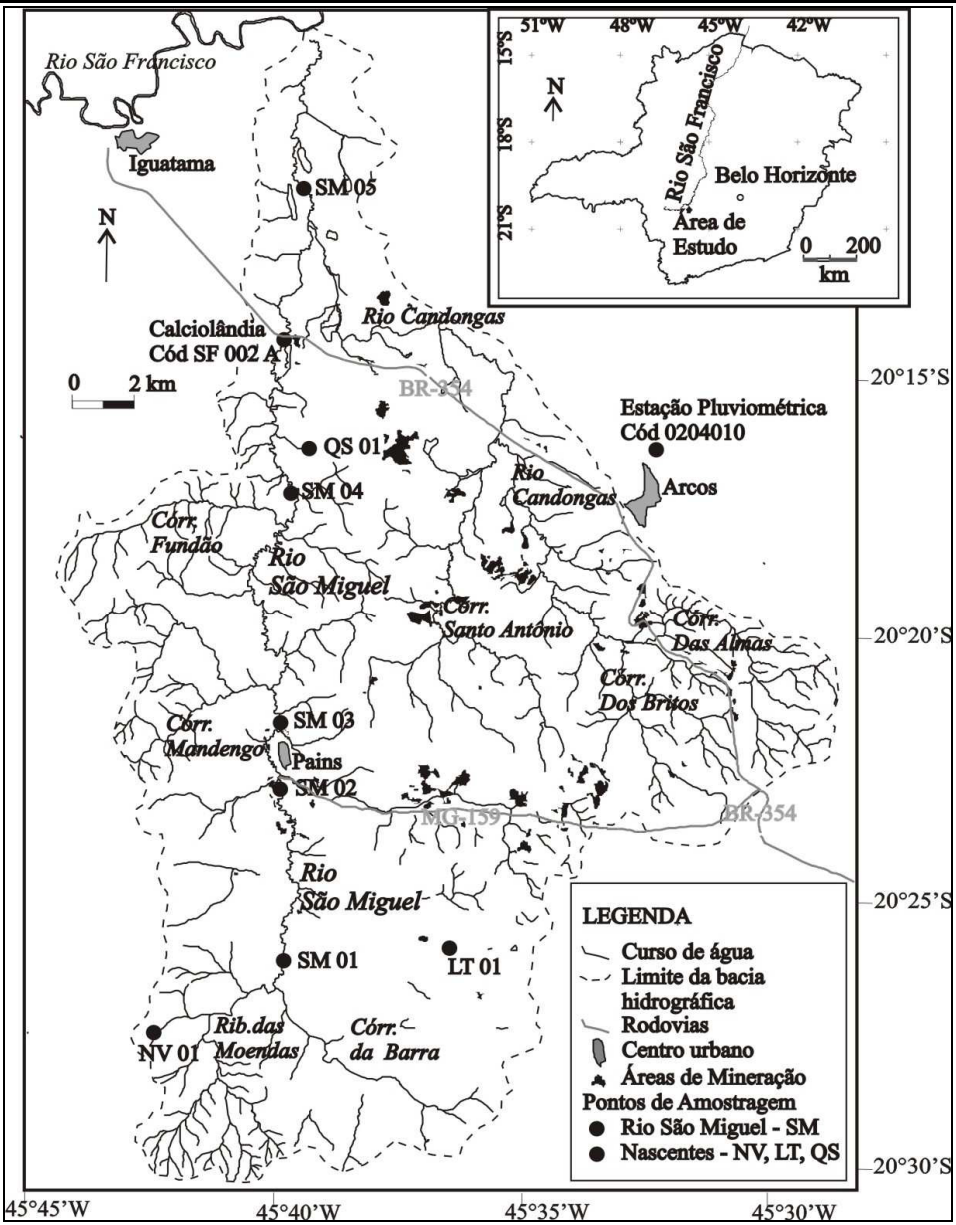

FIGURA 1: Localização da área de estudo, dos pontos de monitoramento e das estações hidrometereológicas

Base Cartográfica: Instituto Brasileiro de Geografia e Estatística - IBGE (1970)²

${ }^{2}$ Instituto Brasileiro de Geografia e Estatística - IBGE. Diretoria de Geodésia e Cartografia. Arcos. $1^{\text {a }}$ Ed., 1970. Folha SF 23-C-I-4, Carta do Brasil, Escala 1: 50.000 . 
HADDAD, E.A. e MAGALHÃES JR., A.P. Influência antrópica na qualidade...

As litologias presentes na bacia são as rochas do Complexo Granito-Gnáissico arqueano e do Grupo Bambuí neoproterozóico. Deste grupo, predominam calcários e dolomitos (FÉLIX \& FREITAS Jr., 2000) que sustentam a paisagem cárstica marcada por feições morfológicas como paredões, torres, mesetas, verrugas, lapiás, dolinas, uvalas, poliés, vales cegos, sumidouros, ressurgências, abismos e cavernas. $\mathrm{O}$ clima é caracterizado pelas seguintes temperaturas médias mensais: mínima de $16,4^{\circ} \mathrm{C}$ em julho e máxima de $22,6^{\circ} \mathrm{C}$ em fevereiro. A média pluviométrica anual é de $1.325 \mathrm{~mm}$ (MENEGASSE et al., 2002).

Conforme a TABELA 1, o uso do solo na bacia se caracteriza pela predominância dos campos utilizados para pastagens, a ocupação urbana apresenta baixa proporção, são $2,7 \mathrm{~km}^{2}$ que representam $0,5 \%$ da área total. As áreas de mineração, atividade econômica expressiva na região, também ocupam pequena extensão areal $(1,5 \%)$, e envolvem os processos da extração das rochas, britagem, moagem, calcinação (queima) que resultam na emissão de poeiras e particulados na atmosfera.

TABELA 1: Classes de usos do solo, área e percentual na bacia hidrográfica do rio São Miguel

\begin{tabular}{l|r|r}
\hline \multirow{2}{*}{ Classe de uso de solo } & \multicolumn{2}{|c}{ Área } \\
\cline { 2 - 3 } & $\mathrm{Km}^{2}$ & $\%$ \\
\hline Pasto & 214,0 & 40,8 \\
\hline Vegetação (Mata) & 143,4 & 27,3 \\
\hline Agricultura & 63,5 & 12,1 \\
\hline Afloramentos rochosos & 60,7 & 11,6 \\
\hline Mineração & 7,8 & 1,5 \\
\hline Solo exposto & 6,2 & 1,2 \\
\hline Plantação de eucalipto & 4,7 & 0,9 \\
\hline Área urbana & 2,6 & 0,5 \\
\hline Outros & 21,4 & 4,1 \\
\hline & $\mathbf{5 2 4 , 6}$ & $\mathbf{1 0 0 , 0}$ \\
\hline
\end{tabular}

Fonte: Cherem, 2006 
HADDAD, E.A. e MAGALHÃES JR., A.P. Influência antrópica na qualidade...

Uma mancha urbana se localiza a NE da bacia e corresponde a uma parte do centro urbano de Arcos (a área muito distante do ponto de monitoramento de qualidade da água). A outra parte corresponde ao centro urbano de Pains, localizado no trecho médio curso do rio São Miguel, 1,5km do ponto de monitoramento SM03 (FIGURA 1). A população urbana deste município em 2000 era de 5.629 habitantes (IBGE, 2005), sendo 77\% abastecida pela rede geral de fornecimento de água, $21 \%$ por poços artesianos e menos de $2 \%$ por outras formas de abastecimento. Cerca de $70 \%$ dos domicílios possuíam rede geral de esgoto em 2000 (IBGE, 2005). Os efluentes são lançados diretamente nos corpos d'água e nos sumidouros, e não há estação de tratamento de esgoto (SERVIÇO AUTÔNOMO DE ÁGUA E ESGOTO - SAAE, 2004).

\section{Resultados}

Os resultados de todos os parâmetros utilizados no monitoramento no rio se encontram no APÊNDICE A, os resultados das nascentes, da Estação Calciolândia e de pluviometria e vazão no período se apresentam no APÊNDICE B. Serão discutidos adiante aqueles que tiveram alterações relacionadas às atividades antrópicas: Coliformes Termotolerantes (CT), Oxigênio Dissolvido (OD), Fósforo Total (PT), e Turbidez.

\section{Coliformes termotolerantes}

Os resultados das concentrações de CT registrados nos pontos de monitoramento atingiram valores superiores aos das nascentes e denota alterações na qualidade da água natural (TABELA 2). Os valores mais elevados ocorreram em dezembro e março quando houve precipitação no dia e momento da coleta e aumento da vazão no rio. Esta relação direta foi apontada no trabalho de Dussart-Baptista et al. (2003) e Little et al. (2003) que observaram picos nas concentrações de CT durante eventos chuvosos. As fontes não pontuais de poluição do meio rural se devem à presença nos solos de material fecal animal relacionado à 
HADDAD, E.A. e MAGALHÃES JR., A.P. Influência antrópica na qualidade... pecuária bovina, elas se localizam nas áreas dos pontos SM 01, 02 e 05, distantes do centro urbano de Pains (FIG.1). O incremento na água se relaciona ao armazenamento de CT nos solos associada à capacidade de movimentação destes organismos por mecanismos de transporte hidrológico (HUNTER et al., 1999). No ponto SM 03 em setembro, as concentrações atingiram o valor da máxima registrado no ponto e em todo rio, mesmo sem chuva na hora da coleta, fato que se deve às fontes pontuais de lançamento de esgotos do centro urbano de Pains, independente das chuvas.

TABELA 2: Coliformes termotolerantes (NMP/100ml) e estatística descritiva

\begin{tabular}{|c|c|c|c|c|c|}
\hline & SM 01 & SM 02 & SM 03 & SM 04 & SM 05 \\
\hline 19/abr/2005 & 130 & 130 & 5000 & 2200 & 110 \\
\hline $15 / \mathrm{mai} / 2005$ & 800 & 500 & 16000 & 110 & 230 \\
\hline 19/jun/2005 & 280 & 70 & 170 & 1100 & 350 \\
\hline 18/jul/2005 & 1700 & 1100 & 21 & 19 & 140 \\
\hline $15 /$ ago/2005 & 140 & 350 & 11 & 170 & 110 \\
\hline $19 /$ set $/ 2005$ & 230 & 220 & 90000 & 1300 & 80 \\
\hline $18 /$ out/2005 & 220 & 170 & 17000 & 50 & 500 \\
\hline 20/nov/2005 & 11 & 170 & 1600 & 110 & 220 \\
\hline $11 / \mathrm{dez} / 2005$ & 1600 & 1600 & 1600 & 1600 & 1600 \\
\hline 23/jan/2006 & 230 & 170 & 13000 & 130 & 700 \\
\hline $15 / \mathrm{fev} / 2006$ & 500 & 230 & 90000 & 280 & 220 \\
\hline $20 / \mathrm{mar} / 2006$ & 30000 & 500 & 50000 & 3000 & 1100 \\
\hline \multicolumn{6}{|l|}{ Estatística descritiva } \\
\hline $\mathrm{n}$ & 12 & 12 & 12 & 12 & 12 \\
\hline Média Aritmética & 3113 & 311 & 24089 & 547 & 266 \\
\hline Média Geométrica & 408 & 290 & 3077 & 318 & 288 \\
\hline Mediana & 230 & 195 & 5000 & 150 & 220 \\
\hline Mínima & 11 & 70 & 11 & 19 & 80 \\
\hline Máxima & 30000 & 1600 & 90000 & 3000 & 1600 \\
\hline
\end{tabular}

Os valores estatísticos mais elevados se encontram no ponto SM 03, superiores à máxima da Estação Calciolândia, 30.000 $\mathrm{NMP} / 100 \mathrm{ml}$, registrada em abril de 2002 (IGAM, 2005). O 
HADDAD, E.A. e MAGALHÃES JR., A.P. Influência antrópica na qualidade... lançamento de esgotos sanitários e dejetos urbanos de Pains representam a mais significativa fonte de poluição pontual e se relaciona aos elevados valores de CT no ponto SM 03, situado a $1,5 \mathrm{~km}$ de distância a jusante do centro urbano. Ressalta-se que o Programa de Controle da Esquistossomose da Secretaria Municipal de Saúde de Pains ${ }^{3}$ contabilizou 315 casos da doença no ano de 2006 no município; deste total, 204 casos ocorreram na zona urbana, portanto, nas proximidades do trecho SM 03.

\section{Fósforo total}

Os resultados das concentrações do Fósforo Total (PT) nos 5 pontos no rio foram superiores aos obtidos nas nascentes, exceto em maio e abril, e mostram alteração nos níveis de PT das águas naturais (TAB. 3). Segundo Von Sperling (2005), a lixiviação de minerais primários, dissolução de compostos do solo e a decomposição de matéria orgânica podem ser relacionados como causas naturais da origem da presença de elemento nas amostras de águas naturais.

Os valores máximos de PT em todos os 5 pontos ocorreram em junho devido ao fato de grande proporção do transporte de PT no solo ocorrer durante algumas precipitações (ELLISON \& BRETT, 2006). Processo similar foi verificado por Little et al. (2003) que relacionaram as maiores elevações de PT nos rios em áreas agrícolas no Canadá ao escoamento superficial provocado pelos primeiros eventos de chuvas após época seca. No rio São Miguel, a última chuva ocorrera dia 27 de maio, seguida de outra somente após um intervalo de 23 dias, quando choveu $13,3 \mathrm{~mm}$ no dia 19 de junho (dia da coleta). Esta precipitação desencadeou a lixiviação e remoção do elemento do solo e o transporte por escoamento superficial, processo principal da entrada de $\mathrm{P}$ dissolvido na água (NASH \& HALLIWELL, 2000). A proveniência do elemento na água está nas fontes não pontuais da

${ }^{3}$ No prelo. 
HADDAD, E.A. e MAGALHÃES JR., A.P. Influência antrópica na qualidade...

agricultura, devido ao uso de fertilizantes, inseticidas, pesticidas e a presença de excremento de animais nos campos de pecuária (LITTLE et al., 2003). De junho a março, da estação seca para a chuvosa, houve diminuição nos valores, diretamente relacionado à precipitação acumulada, que implicou na diluição do elemento nas águas com o aumento da vazão (janeiro, fevereiro e março).

TABELA 3: Fósforo Total (mg/L) e estatística descritiva

\begin{tabular}{lccccc}
\hline & SM 01 & SM 02 & SM 03 & SM 04 & SM 05 \\
\hline 19/abr/2005 & 0,01 & 0,02 & 0,14 & 0,04 & 0,02 \\
$15 /$ mai/2005 & 0,01 & 0,01 & 0,01 & 0,01 & 0,01 \\
$19 /$ jun/2005 & 0,32 & 0,34 & 0,46 & 0,44 & 0,39 \\
$18 /$ jul/2005 & 0,13 & 0,15 & 0,09 & 0,18 & 0,14 \\
$15 /$ ago/2005 & 0,23 & 0,18 & 0,25 & 0,16 & 0,18 \\
$19 /$ set/2005 & 0,08 & 0,08 & 0,15 & 0,08 & 0,08 \\
$18 /$ out/2005 & 0,09 & 0,06 & 0,14 & 0,10 & 0,06 \\
$20 /$ nov/2005 & 0,15 & 0,13 & 0,10 & 0,12 & 0,11 \\
$11 /$ dez/2005 & 0,10 & 0,09 & 0,14 & 0,15 & 0,14 \\
$23 /$ jan/2006 & 0,11 & 0,05 & 0,04 & 0,07 & 0,03 \\
$15 /$ fev/2006 & 0,10 & 0,10 & 0,11 & 0,08 & 0,05 \\
$20 /$ mar/2006 & 0,08 & 0,08 & 0,06 & 0,10 & 0,10 \\
\hline Estatística descritiva & & & & & \\
\multicolumn{1}{c}{ Média Aritmética } & 0,12 & 0,11 & 0,15 & 0,13 & 0,11 \\
Média Geométrica & 0,08 & 0,08 & 0,10 & 0,09 & 0,07 \\
Mediana & 0,10 & 0,09 & 0,14 & 0,10 & 0,08 \\
Mínima & 0,01 & 0,01 & 0,01 & 0,01 & 0,01 \\
Máxima & 0,32 & 0,34 & 0,46 & 0,44 & 0,39 \\
\hline
\end{tabular}

Espacialmente, a distribuição dos valores de medida de tendência central dos pontos (médias e medianas) tende a decrescer de montante para jusante, exceto entre os pontos SM 02 e SM 03 (TAB.3), onde há ocupação urbana entre eles. Owens \& Walling (2002) verificaram o mesmo padrão em bacia hidrográfica com ocupação urbana. O lançamento de esgotos domésticos, detergentes centro urbano de Pains contribui de forma mais 
HADDAD, E.A. e MAGALHÃES JR., A.P. Influência antrópica na qualidade...

constante e regular em relação aos outros pontos durante todo o ano para entrada de PT no rio. Porém, os valores absolutos observados em junho em todos os pontos do escoamento superficial de fontes difusas da agricultura, representaram as fontes mais significativas para a poluição do curso d'água por este parâmetro.

\section{Oxigênio dissolvido}

Os valores de Oxigênio Dissolvido - OD - dos meses de maio, junho e das nascentes não foram computados devido a erros de leituras do equipamento em campo. O valor máximo obtido em campo foi de $8,8 \mathrm{mg} / \mathrm{L}$ no ponto SM 01 em novembro, e foi usado como referência para o valor de OD de águas naturais na bacia do rio São Miguel. Os valores na TABELA 4 mostram que há um decréscimo do valor de $8,8 \mathrm{mg} / \mathrm{L}$ em todos os pontos, indicando mudanças nas condições do parâmetro OD nas águas do rio.

O decréscimo da vazão no final da estação seca (de julho a outubro) foi acompanhado pelo decaimento de OD (setembro e outubro foram os meses críticos). A partir de novembro, com o início das chuvas e aumento das vazões, os valores de OD se elevaram, com exceção do mês de fevereiro, associado aos elevados valores de CT no ponto SM 03 neste dia (TAB.2).

O padrão de distribuição espacial de OD mostra decréscimo em todos os valores estatísticos (médias, mediana, mínima e máxima) do ponto SM 01 para o ponto SM 03, este com os valores mais críticos dentre os pontos (TAB.4). A jusante do ponto SM 03 o acréscimo dos valores denotam que o rio melhora suas condições sem, no entanto, atingir as condições de montante. Nos pontos SM 04 e SM 05 este aumento está relacionado às contribuições dos córregos do Mandengo e do Fundão, assim como do rio Candongas (FIG.1).

O rebaixamento na concentração de $\mathrm{OD}$ no ponto SM 03 se deve à poluição orgânica nesta parte do rio, que se relaciona às fontes pontuais de lançamentos de esgotos e efluentes domésticos 
HADDAD, E.A. e MAGALHÃES JR., A.P. Influência antrópica na qualidade... urbanos de Pains. O excesso de cargas orgânicas se dá com elevadas contagens de CT bem como as maiores concentrações de PT que na sua forma orgânica resulta no decréscimo de OD (TOLEDO \& NICOLELLA, 2002). O ponto SM 03 foi o único que apresentou correlação negativa entre CT e OD $(-0,23)$. Pontualmente, a relação indireta entre os parâmetros se deu em novembro nos pontos SM 01 e 02 , e em janeiro neste último, revelando que a relação entre estes parâmetros se evidenciou somente com elevadas contagens de CT, pois os picos de CT de $90.000 \mathrm{NMP} / 100 \mathrm{mg} / \mathrm{L}$ (TAB.2) se associaram aos menores valores de OD registrados em todo o monitoramento, em setembro $(3,0 \mathrm{mg} / \mathrm{L})$ e em fevereiro $(3,4 \mathrm{mg} / \mathrm{L})$. Eles são os menores valores dentre todos os pontos de monitoramento e inferiores à concentração mínima registrada na estação Calciolândia (5,5mg/L em outubro de 2003).

TABELA 4 - Oxigênio dissolvido (mg/L) e estatística descritiva

\begin{tabular}{lccccc}
\hline & SM01 & SM02 & SM03 & SM04 & SM05 \\
\hline 19/abr/2005 & 4,4 & 4,2 & 5,0 & 5,4 & 4,0 \\
18/jul/2005 & 8,4 & 7,5 & 6,2 & 5,8 & 5,5 \\
15/ago/2005 & 6,8 & 6,4 & 3,7 & 5,7 & 6,2 \\
19/set/2005 & 5,6 & 5,5 & 3,0 & 5,6 & 5,1 \\
18/out/2005 & 5,5 & 4,9 & 3,9 & 4,9 & 4,8 \\
20/nov/2005 & 8,8 & 7,5 & 6,0 & 4,6 & 6,5 \\
$11 /$ dez/2005 & 6,2 & 6,3 & 6,2 & 7,3 & 7,6 \\
23/jan/2006 & 8,2 & 8,1 & 7,1 & 6,9 & 6,1 \\
15/fev/2006 & 5,6 & 5,2 & 3,4 & 5,5 & 5,5 \\
20/mar/2006 & 7,8 & 7,7 & 5,5 & 6,4 & 6,9 \\
\hline Estatística descritiva & & & & & \\
n & 10 & 10 & 10 & 10 & 10 \\
\multicolumn{1}{c}{ Média Aritmética } & 6,7 & 6,2 & 4,9 & 5,7 & 5,7 \\
Média Geométrica & 6,6 & 6,2 & 4,8 & 5,8 & 5,7 \\
Mediana & 6,5 & 6,3 & 5,0 & 5,6 & 5,5 \\
Mínima & 4,4 & 4,2 & 3,0 & 4,6 & 4,0 \\
Máxima & 8,8 & 8,1 & 7,1 & 7,3 & 7,6 \\
\hline
\end{tabular}


HADDAD, E.A. e MAGALHÃES JR., A.P. Influência antrópica na qualidade...

\section{Turbidez}

Os valores de turbidez nas águas estão na faixa entre 1,1 a 2,15 UNT obtidas nas nascentes, e os valores das máximas nos pontos indicam fortes alterações na qualidade da água natural provenientes de atividades antrópicas (TABELA 5) ${ }^{4}$.

TABELA 5 - Turbidez (UNT) e estatística descritiva

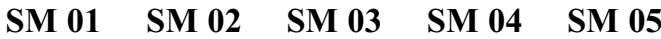

\begin{tabular}{lrrrrr}
\hline 18/jul/2005 & 5,29 & 3,89 & 1,96 & $\ldots$ & 4,57 \\
$15 / \mathrm{ago} / 2005$ & 2,98 & 4,66 & 1,83 & 3,25 & 5,11 \\
$19 / \mathrm{set} / 2005$ & 8,49 & 2,66 & 2,41 & 2,71 & 10,65 \\
$18 / \mathrm{out} / 2005$ & 3,4 & 2,04 & 3,30 & 1,39 & 5,10 \\
20/nov/2005 & 5,92 & 4,92 & 4,36 & 3,06 & 22,90 \\
$11 / \mathrm{dez} / 2005$ & 42,53 & 23,06 & 36,58 & 44,57 & 63,06 \\
$23 / \mathrm{jan} / 2006$ & 7,46 & 5,7 & 5,38 & 4,92 & 9,24 \\
$15 / \mathrm{fev} / 2006$ & 7,39 & 7 & 2,79 & 3,93 & 8,46 \\
$20 /$ mar/2006 & 350 & 28,68 & 9,30 & 8,00 & 56,31 \\
\hline Estatística descritiva & & & & & \\
$\mathrm{n}$ & 9 & 9 & 9 & 9 & 9 \\
Média Aritmética & 48,2 & 9,2 & 7,5 & 9,0 & 20,6 \\
Média Geométrica & 10,92 & 6,16 & 4,41 & 4,75 & 12,61 \\
Mediana & 7,39 & 4,92 & 3,3 & 3,59 & 9,24 \\
Mínima & 2,98 & 2,04 & 1,83 & 1,39 & 4,57 \\
Máxima & 350 & 28,68 & 36,58 & 44,57 & 63,06 \\
\hline
\end{tabular}

As variações temporais mais significativas durante o ano do monitoramento se deveram às precipitações no momento das coletas em dezembro e março, ocasionando elevação conjunta da

${ }^{4}$ Os dados abrangem o período de julho a março, devido ao atraso na entrega do turbidímetro pelo fornecedor responsável. A amostra de julho do ponto SM 04 foi extraviada, o recipiente furou e não suportou o conteúdo da amostra até a sua devida leitura. 
HADDAD, E.A. e MAGALHÃES JR., A.P. Influência antrópica na qualidade...

turbidez nos 5 pontos (TAB.5). O aumento da turbidez em eventos chuvosos se deve ao impacto e remoção de partículas de solos expostos pela ausência de cobertura vegetal, e o posterior transporte por escoamento superficial para os corpos d'água (DUSSART-BAPTISTA et al., 2003; SILVA et al., 2003; VALDES et al., 2005).

Espacialmente, a distribuição da turbidez observada de montante para a jusante nos pontos é diferente da distribuição verificada para $\mathrm{CT}$, PT. O padrão espacial mostra que as áreas críticas segundo valores estatísticos estão nos pontos SM 01 e SM 05, (TAB.5). A presença de vegetação ripária junto aos pontos SM 02,03 e 04 contribui para os valores de turbidez relativamente inferiores aos dos pontos SM 01 e 05 .

O ponto SM 01 apresentou a maior média aritmética, e a maior máxima, registrada durante a precipitação em março (350 UTN). A desproporção elevada atesta a presença de um ou mais focos de erosão acelerada (voçorocamento), cuja origem se relaciona ao manejo inadequado do solo para a atividade agropecuária, aliado à ausência de vegetação nas margens do curso d'água.

O ponto mais a jusante, SM 05, apresentou os mais elevados valores de mínima, média geométrica e mediana (TAB.5), relacionados a erosão laminar acelerada mais intensa e à maior vazão deste trecho no rio. As causas deste comportamento estão na concentração de amplas áreas agrícolas e agropecuárias a montante do ponto, localizadas no baixo curso do rio Candongas e São Miguel (CHEREM, 2006). Estas áreas submetidas à aragem periódica e ao uso e manejo inadequados do solo, bem como de pastagens mal conservadas, que resultam em áreas de solo exposto, e representam zonas potenciais de elevada erosão laminar. São áreas fornecedoras de matérias em solução e suspensão e definem a deteriorização da qualidade da água no ponto SM 05. Outro problema observado foi uma relação direta do aumento da turbidez e do número de CT. Este fato indica a influência direta do escoamento superficial, laminar e concentrado na remoção de 
HADDAD, E.A. e MAGALHÃES JR., A.P. Influência antrópica na qualidade... partículas do solo e de fezes de animais no meio rural, principalmente nos períodos de chuvas. Nos pontos SM 01 e SM 05, nos dias das chuvas de dezembro e março, os picos de turbidez coincidiram com os maiores valores de concentrações de CT registrados em cada ponto (TAB.2). Segundo Dussart-Baptista et al. (2003), apesar de baixos valores de turbidez não significar ausência de contaminação por bactérias, valores elevados de turbidez potencializam a possível presença de organismos patogênicos nas águas (SILVA et al., 2003).

\section{Conclusões}

A pesquisa possibilitou, como foco principal dos estudos, identificar e avaliar relações existentes entre a qualidade das águas superficiais e as atividades humanas desenvolvidas na bacia hidrográfica do rio São Miguel, denotando influências antrópicas no estado de suas águas.

A ocupação urbana se dá em pequena extensão areal da bacia e representa um baixo percentual do uso do solo, mas é responsável pelo principal foco de poluição pontual. A forma direta e in natura pela qual os esgotos do centro urbano de Pains são lançados nas águas, constituem o principal problema de poluição delas. No trecho imediatamente a jusante da cidade, foram registradas as alterações quantitativas mais elevadas no número de coliformes termotolerantes, a maior elevação nos teores de fósforo total e rebaixamento mais significativo nos níveis de oxigênio dissolvido na água do rio São Miguel.

Estas considerações indicam a necessidade de se avaliar medidas para reduzir a carga de lançamentos de esgotos não tratados no rio, e controlar fontes de poluição pontual, apontando a necessidade de construção de Estação de Tratamento de Esgoto à jusante do centro urbano de Pains. A contaminação microbiológica implica no comprometimento do uso da água, restringindo, segundo padrões legais nacionais, ao uso para navegação e harmonia paisagística (que não constituem usos relevantes neste 
HADDAD, E.A. e MAGALHÃES JR., A.P. Influência antrópica na qualidade... caso). Porém, o contato primário de pessoas com a água contaminada foi revelado pelas ocorrências de casos de esquistossomose, registrado na zona urbana de Pains.

Outro efeito da relação entre uso solo e qualidade da água na bacia hidrográfica se deve a fontes não pontuais de poluição. Os campos utilizados para agricultura e pecuária compõem a paisagem rural predominante na área na bacia. A substituição da vegetação natural por estes campos provocou a devastação de parte da vegetação de topos, de encostas e ribeirinha, facilitando a erosão do solo e o aporte de carga sedimentar ao canal fluvial. Os efeitos deletérios na água se fizeram notar durante eventos chuvosos com elevação da turbidez nos trechos do alto e do baixo curso do rio. Neste último, há um claro predomínio do uso do solo para a agricultura. Nos eventos de precipitação, o aumento da turbidez, acompanhada pelo incremento do número de coliformes termotolerantes na água caracteriza uma situação de maior susceptibilidade das águas a poluição hídrica na época das chuvas, com tendências de piora na sua qualidade. Deve-se observar mais detalhadamente o cuidado com a manutenção e recuperação vegetacional nas zonas ripárias, o que exige o mapeamento em detalhe das áreas onde esta vegetação foi retirada.

Apesar da qualidade das águas superficiais refletir os usos urbanos e agrícolas na bacia, não se mostra um indicador eficiente da principal atividade econômica regional: a mineração do calcário. A mineração é também uma das principais atividades impactantes sobre o patrimônio cárstico da bacia. Porém, não foi verificado nenhum comprometimento da qualidade da água pela mineração, pelo menos a partir do conjunto dos indicadores analisados.

\section{Agradecimentos}

Os autores agradecem à Fundação de Amparo à Pesquisa de Minas Gerais (FAPEMIG) e à Coordenação de Aperfeiçoamento de Pessoal de Nível Superior (CAPES) pelo suporte financeiro do projeto. 
HADDAD, E.A. e MAGALHÃES JR., A.P. Influência antrópica na qualidade...

\section{Referências bibliográficas}

BOURLON, N; BERTHON, D. 1998. Desenvolvimento sustentável e gerenciamento das bacias hidrográficas na América Latina. In: Água em Revista. CPRM, Ano VI, n.10, pp. 16-22, jun 1998.

BOTELHO, R.G.M. \& SILVA, A.S. Bacia hidrográfica e qualidade ambiental. In: VITTE, A.C. e GUERRA, A.J.T. (Org.) Reflexões sobre a Geografia Física no Brasil. Bertrand Brasil: Rio de Janeiro, 2004. pp.153-192.

BRASIL. Lei 9.433, de 08 de janeiro de 1997. Institui a Política Nacional de Recursos Hídricos, cria o Sistema Nacional de Gerenciamento de Recursos Hídricos, regulamenta o inciso XIX do art. 21 da Constituição Federal, e altera o art. $1^{\circ}$ da Lei 8.001, de 13 de março de 1990, que modificou a Lei $\mathrm{n}^{\circ} 7.990$, de 28 de dezembro de 1989. Diário Oficial da República Federativa do Brasil, Brasília, 1997.

CHEREM, L.F. Atlas cartográfico para a gestão ambiental de médias bacias hidrográficas: proposição conceitual-metodológica e o estudo de caso da bacia do rio São Miguel - Alto São Francisco/MG. 2006. 85f. Monografia (Graduação em Geografia) - Instituto de Geociências, Universidade Federal de Minas Gerais, Belo Horizonte, 2006.

DUSSART-BAPTISTA, L.; MASSEIA, N.; DUPONTA, J.-P.; JOUENNE, T. Transfer of bacteria-contaminated particles in a karst aquifer: evolution of contaminated materials from a sinkhole to a spring. In: Journal of Hydrology. v. 284, pp.285-295, 2003.

ELLISON, M.E. \& BRETT, M.T. Particulate phosphorus bioavailability as a function of stream flow and land cover. In: Water Research. n.40, pp.1258-1268, 2006.

FÉLIX, A.A. \& FREITAS JÚNIOR, R.L. Mapeamento geológico e hidrogeológico da bacia hidrográfica do rio São Miguel - Alto São Francisco, Estado de Minas Gerais. 2000. 105f. (Trabalho 
HADDAD, E.A. e MAGALHÃES JR., A.P. Influência antrópica na qualidade...

Geológico de Graduação) Instituto de Geociências, Universidade Federal de Minas Gerais, Belo Horizonte, 2000.

HUNTER, C.; PERKINS, TRANTER, J; GUNN, J. Agricultural land-use effects on the indicator bacterial quality of an upland stream in the Derbyshire Peak District in the U.K. In: Water Research. v. 33, n.17, pp.3577-3586, 1999.

INSTITUTO BRASILEIRO DE GEOGRAFIA E ESTATÍSTICA IBGE. IBGE Cidades 2005. Rio de Janeiro: IBGE, 2005. Disponível em: $<$ http://www.ibge.gov.br >. Acesso em: 11 abr. 2006.

INSTITUTO MINEIRO DE GESTÃO DAS ÁGUAS - IGAM. Relatório de monitoramento das águas superficiais na Bacia do Rio São Francisco em 2004: Bacia do Rio São Francisco - Sul. Belo Horizonte: IGAM, 2005.180p.

LAMB, J.C. Water quality and its control. New York: Wiley, 1985. pp.1-32; 47-89; 106-127; 142-160; 199-216.

LITTLE, J.L.; SAFFRAN, K.A.; FENT, L. Land Use and Water Quality Relationships in the Lower Little Bow River Watershed, Alberta, Canada. In: Water Quality Research Journal of Canada. v. 38, n.4, pp. 563-584, 2003.

MAGALHÃES Jr., A. Os indicadores como instrumentos de apoio à consolidação da gestão participativa da água no Brasil: realidades e perspectivas no contexto dos Comitês de Bacia Hidrográfica. 2003. Tese (Doutorado no Centro de Desenvolvimento Sustentável) Universidade Nacional de Brasília, Brasília, 2003.

MENEGASSE, L.N.; GONÇALVES, J.M.; FANTINEL, L.M. Disponibilidades hídricas na Província Cárstica de Arcos Pains e Doresópolis - Alto São Francisco, Minas Gerais, Brasil. In: Revista Águas Subterrâneas. n.16, maio/2002, pp.1-19. 
HADDAD, E.A. e MAGALHÃES JR., A.P. Influência antrópica na qualidade...

MEYBECK, M. \& HELMER, R. An introduction to water quality. In: CHAPMAN, D. (Org.). Water Quality Assessments - A Guide to Use of Biota, Sediments and Water in Environmental Monitoring. $2^{\text {nd }}$ Ed. Cambridge: Chapman \& Hall, 1996. (Edited by Deborah Chapman 1992, 1996 UNESCO/WHO/UNEP)

NASH, D.M.; HALLIWELL, D.J. Tracing phosphorous transferred from grazing land to water. In: Water Research. v.34, n.7, pp. 1975-1985, 2000.

OWENS, P.N.; WALLING, D.E. The phosphorus content of fluvial sediment in rural and industrialized river basins. In: Water Research. v. 36, pp.685-701, 2002.

TOLEDO, L.G.; NICOLELLA, G. Índice de qualidade de água em microbacia sob uso agrícola e urbano. In: Scientia Agricola. v.59, n.1, pp.181-186, jan/mar 2002.

SERVIÇO AUTÔNOMO DE ÁGUA E ESGOTO - SAAE. Relatório Anual de Atividades - Pains, 2004.

SILVA, A.M., SCHULZ, H.E. e CAMARGO, P.B. Erosão e Hidrossedimentologia em Bacias Hidrográficas. São Carlos: RiMa, 2003. pp.11-45; 83-91.

VALDES, D.; DUPONT, J.P.; MASSEI，N.; LAIGNEL，B; RODET, J. Analysis of karst hydrodynamics through comparison of dissolved and suspended solids' transport. In: Compter Rendus Geoscience. v.337. pp.1365-1374, 2005.

VON SPERLING, M. Introdução à qualidade das águas e ao tratamento de esgotos. v.1. 3ed. Belo Horizonte: UFMG, Departamento de Engenharia Sanitária e Ambiental, 2005.

WORLD HEALTH ORGANIZATION - WHO. Guidelines for drinking-water quality. $2^{\text {nd }}$. Ed. Geneve: WHO, 1993. v.1 Recommendations. pp.1-15; 39-57. 
HADDAD, E.A. e MAGALHÃES JR., A.P. Influência antrópica na qualidade...

\section{APÊNDICE A}

\section{Resultados dos parâmetros monitorados no rio São Miguel - abril/2005 a março/2006}

\begin{tabular}{|c|c|c|c|c|c|c|c|c|c|c|c|c|}
\hline \multicolumn{13}{|c|}{ SM 01} \\
\hline Data & $19 / \mathrm{abr}$ & $15 /$ mai & 19/jun & $18 /$ jul & 15/ago & $19 /$ set & $18 /$ out & $20 /$ nov & $11 / \mathrm{dez}$ & $23 /$ jan & $15 /$ fev & $20 /$ mar \\
\hline Horas & $\ldots$ & $16: 15$ & $15: 00$ & $16: 30$ & $09: 30$ & $09: 45$ & $09: 40$ & $08: 30$ & $10: 00$ & $08: 50$ & $11: 24$ & 07:00 \\
\hline Vazão $\mathbf{~ m}^{3} / \mathbf{s}$ & 0,37 & 0,50 & 0,47 & 0,34 & 0,25 & 0,23 & 0,13 & 0,22 & 0,90 & 0,59 & 0,47 & 1,00 \\
\hline $\mathbf{T}\left({ }^{\circ} \mathrm{C}\right)$ & 21,2 & 22,7 & 20,7 & 18,8 & 18,8 & 21,5 & 22,6 & 22 & 21,7 & 21,2 & 23,2 & 21,7 \\
\hline pH & 8 & 8 & 8,6 & 8,8 & 8,9 & 8,8 & 8,1 & 8,2 & 8,3 & 8,2 & 7,9 & 7,7 \\
\hline OD $(\mathrm{mg} / \mathrm{L})$ & 4,4 & 16,5 & 21 & 8,4 & 6,8 & 5,6 & 5,5 & 8,8 & 6,2 & 8,2 & 5,6 & 7,8 \\
\hline $\mathrm{CE}(\mathrm{mS})$ & 0,37 & 0,335 & 0,321 & 0,304 & 0,329 & 0,331 & 0,328 & 0,342 & 0,345 & 0,366 & 0,349 & 0,204 \\
\hline Turbidez (NTU) & $\cdots$ & $\ldots$ & $\ldots$ & 5,29 & 2,98 & 8,49 & 3,4 & 5,92 & 42,53 & 7,46 & 7,39 & 350 \\
\hline Cd Total (mg/L) & $<0,0005$ & $<0,0005$ & $<0,0005$ & 0,001 & $<0,0005$ & 0,0006 & $<0,0005$ & $<0,0005$ & $<0,0005$ & $<0,0005$ & $<0,0005$ & $<0,0005$ \\
\hline Pb Total (mg/l) & $<0,005$ & $<0,005$ & $<0,005$ & $<0,005$ & $<0,005$ & $<0,005$ & $<0,005$ & $<0,005$ & $<0,005$ & $<0,005$ & $<0,005$ & 0,023 \\
\hline Coliformes (100mg) & 130 & 800 & 280 & 1700 & 140 & 230 & 220 & 11 & $>1600$ & 230 & 500 & 30000 \\
\hline DBO $(\mathrm{mg} / \mathrm{L})$ & 2 & $<2$ & $<2$ & 2 & 2 & 3 & $<2$ & $<2$ & $<2$ & $<2$ & $<2$ & 3 \\
\hline DQO (mg/L) & 8 & 9 & 7 & 21 & 7 & 26 & $<5$ & $<5$ & $<5$ & $<5$ & $<5$ & 28 \\
\hline P Total (mg/L P) & 0,01 & $<0,01$ & 0,32 & 0,13 & 0,23 & 0,08 & 0,09 & 0,15 & 0,1 & 0,11 & 0,1 & 0,08 \\
\hline Nitrato (mg N/L) & 0,45 & 0,33 & 0,17 & 0,08 & 0,16 & 0,08 & 0,19 & 0,17 & 0,06 & 0,3 & 0,27 & 0,38 \\
\hline Zn Total (mg/L) & 1,18 & 1,02 & 0,06 & 0,07 & 0,12 & 0,12 & 0,08 & 0,11 & 0,08 & 0,06 & 0,21 & 0,09 \\
\hline
\end{tabular}

SM 02

\begin{tabular}{|c|c|c|c|c|c|c|c|c|c|c|c|c|}
\hline $\begin{array}{r}\text { Data } \\
\text { Horas }\end{array}$ & $\begin{array}{c}19 / \mathrm{abr} \\
\ldots\end{array}$ & $\begin{array}{c}15 / \text { mai } \\
17: 20\end{array}$ & $\begin{array}{c}19 / \text { jun } \\
16: 50\end{array}$ & $\begin{array}{l}18 / \text { jul } \\
17: 50\end{array}$ & $\begin{array}{c}\text { 15/ago } \\
11: 00\end{array}$ & $\begin{array}{l}19 / \text { set } \\
11: 00\end{array}$ & $\begin{array}{l}18 / \text { out } \\
11: 05\end{array}$ & $\begin{array}{c}20 / \text { nov } \\
10: 05\end{array}$ & $\begin{array}{c}11 / \mathrm{dez} \\
11: 15\end{array}$ & $\begin{array}{c}23 / \text { jan } \\
10: 00\end{array}$ & $\begin{array}{l}15 / \mathrm{fev} \\
13: 00\end{array}$ & $\begin{array}{c}20 / \text { mar } \\
08: 20\end{array}$ \\
\hline Vazão $\mathrm{m}^{3} / \mathbf{s}$ & 0,77 & 1,87 & 1,45 & 1,9 & 0,81 & 0,57 & 0,52 & 0,6 & 1,92 & 1,1 & 1,01 & 3,29 \\
\hline $\mathbf{T}\left({ }^{\circ} \mathbf{C}\right)$ & 24,2 & 21,1 & 20 & 18,9 & 19,5 & 22,2 & 23,1 & 22,8 & 22,3 & 22,4 & 24 & 22 \\
\hline pH & 7,8 & 7,2 & 8,3 & 8,3 & 8,7 & 8,6 & 7,9 & 8,2 & 8,2 & 8,5 & 7,8 & 7,9 \\
\hline OD (mg/L) & 4,2 & 12,1 & 10,9 & 7,5 & 6,4 & 5,5 & 4,9 & 7,5 & 6,3 & 8,1 & 5,2 & 7,7 \\
\hline $\mathrm{CE}(\mathrm{mS})$ & 0,348 & 0,334 & 0,313 & 0,305 & 0,324 & 0,303 & 0,333 & 0,342 & 0,348 & 0,341 & 0,345 & 0,346 \\
\hline Turbidez (NTU) & $\ldots$ & $\ldots$ & $\ldots$ & 3,89 & 4,66 & 2,66 & 2,04 & 4,92 & 23,06 & 5,7 & 7 & 28,68 \\
\hline Cd Total (mg/L) & $<0,0005$ & $<0,0005$ & $<0,0082$ & $<0,0005$ & $<0,0005$ & $<0,0005$ & $<0,0005$ & $;<0,0005$ & $<0,0005$ & $;<0,0005$ & $<<0,0005$ & $5<0,0005$ \\
\hline Pb Total (mg/l) & $<0,005$ & $<0,005$ & $<0,005$ & $<0,005$ & 0,009 & $<0,005$ & $<0,005$ & $<0,005$ & $<0,005$ & $<0,005$ & $<0,005$ & 0,008 \\
\hline Coliformes (100mg) & 130 & 500 & 70 & 1100 & 350 & 220 & 170 & 170 & $>1600$ & 170 & 230 & 500 \\
\hline DBO (mg/L) & $<2$ & $<2$ & $<2$ & 3 & 2 & $<2$ & $<2$ & $<2$ & $<2$ & $<2$ & $<2$ & $<2$ \\
\hline DQO (mg/L) & 17 & $<5$ & 11 & $<5$ & 7 & 16 & 7 & 7 & 8 & $<5$ & 8 & 5 \\
\hline P Total (mg/L P) & 0,02 & $<0,01$ & 0,34 & 0,15 & 0,18 & 0,08 & 0,06 & 0,13 & 0,09 & 0,05 & 0,1 & 0,08 \\
\hline Nitrato (mg N/L) & 4,5 & 0,35 & 0,17 & 0,07 & 0,19 & $<0,01$ & 0,17 & 0,12 & 0,11 & 0,06 & 0,4 & 0,44 \\
\hline Zn Total (mg/L) & 1,36 & 1,13 & 0,06 & 0,12 & 0,092 & 0,14 & 0,08 & 0,1 & 0,03 & 0,06 & 0,19 & 0,07 \\
\hline
\end{tabular}


HADDAD, E.A. e MAGALHÃES JR., A.P. Influência antrópica na qualidade...

\begin{tabular}{l|cccccccccccc}
\hline \multicolumn{10}{c}{ Sata } & \multicolumn{10}{c}{ SM } \\
\hline \multicolumn{1}{c}{ Horas } & $18 /$ abr & $15 /$ mai & $19 /$ jun & $18 /$ jul & $15 /$ ago & $19 /$ set & $18 /$ out & $20 /$ nov & $11 /$ dez & $23 /$ jan & 15 -fev & $20 /$ mar \\
\multicolumn{1}{c}{} & & $15: 00$ & $13: 30$ & $13: 30$ & $12: 00$ & $12: 00$ & $13: 00$ & $11: 00$ & $12: 40$ & $11: 15$ & $14: 20$ & $10: 00$ \\
\hline Vazão m ${ }^{3} / \mathbf{s}$ & 1,34 & 1,68 & 1,52 & 1,13 & 1,02 & 0,98 & 0,64 & 0,97 & 4,6 & 1,49 & 1,39 & 4,11 \\
T ( ${ }^{\circ}$ C) & 22,9 & 22,4 & 21,5 & 20,9 & 20,1 & 22,5 & 23,5 & 23,2 & 22,8 & 22,3 & 24,3 & 22,4 \\
pH & 7,7 & 7,3 & 8,1 & 8,1 & 8,4 & 8,4 & 7,6 & 7,5 & 7,6 & 7,9 & 7,4 & 7,7 \\
OD (mg/L) & 5 & 12,6 & 21,9 & 6,2 & 3,7 & 3 & 3,9 & 6 & 6,2 & 7,1 & 3,4 & 5,5 \\
CE (mS) & 0,406 & 0,365 & 0,354 & 0,349 & 0,352 & 0,366 & 0,383 & 0,398 & 0,389 & 0,418 & 0,403 & 0,435 \\
Turbidez (NTU) & $\ldots$ & $\ldots$ & $\ldots$ & 1,96 & 1,83 & 2,41 & 3,3 & 4,36 & 36,58 & 5,38 & 2,79 & 9,3 \\
Cd Total (mg/L) & $<0,0005<0,0005<0,0005<0,0005<0,0005<0,0005<0,0005<0,0005<0,0005<0,0005<0,0005<0,0005$ \\
Pb Total (mg/l) & $<0,008$ & $<0,005$ & $<0,005$ & $<0,005$ & $<0,005$ & $<0,005$ & $<0,005$ & $<0,005$ & 0,006 & $<0,005$ & $<0,005$ & 0,014 \\
Coliformes (100mg) & 5000 & $>16000$ & 170 & 21 & 11 & 90000 & 17000 & 1600 & $>1600$ & 13000 & 90000 & 50000 \\
DBO (mg/L) & 2 & $<2$ & 3 & 3 & $<2$ & 2 & 2 & 2 & $<2$ & 2 & 2 & $<2$ \\
DQO (mg/L) & 15 & 10 & 11 & $<5$ & $<5$ & 9 & 9 & 36 & 10 & 5 & 5 & 7 \\
P Total (mg/L P) & 0,14 & $<0,01$ & 0,46 & 0,09 & 0,25 & 0,15 & 0,14 & 0,1 & 0,14 & 0,04 & 0,11 & 0,06 \\
Nitrato (mg N/L) & 8,87 & 0,57 & 0,22 & 0,36 & 0,56 & 0,03 & 0,27 & 0,34 & 0,12 & 0,11 & 0,99 & 0,71 \\
Zn Total (mg/L) & 1,06 & 1,11 & 0,08 & 0,12 & 0,228 & 0,15 & 0,1 & 0,21 & 0,05 & 0,05 & 0,15 & 0,08 \\
\hline
\end{tabular}

\begin{tabular}{l|cccccccccccc}
\hline \multicolumn{1}{c}{ Data } & \multicolumn{10}{c}{ SM 04 } \\
\hline \multicolumn{1}{c}{ Horas } & $18 /$ abr & $15 /$ mai & $19 /$ jun & $18 /$ jul & $15 /$ ago & $19 /$ set & $18 /$ out & $20 /$ nov & $11 /$ dez & $23 /$ jan & $15 /$ fev & $20 /$ mar \\
\hline & $\ldots$ & $13: 45$ & $12: 30$ & $12: 10$ & $13: 30$ & $13: 20$ & $14: 00$ & $13: 00$ & $13: 45$ & $12: 10$ & $15: 20$ & $11: 30$ \\
\hline Vazão (m $\left.{ }^{3} / \mathbf{s}\right)$ & 1,96 & 2,73 & 1,99 & 1,44 & 1,03 & 1,02 & 0,73 & 1,14 & 7,43 & 2,34 & 2,34 & 3,33 \\
T ( ${ }^{\circ}$ C) & 23,2 & 22 & 21,4 & 18,9 & 19,7 & 22,6 & 24,2 & 24,7 & 23,2 & 23,2 & 24,9 & 23 \\
pH & 3 & 7,3 & 8,1 & 8,5 & 8,7 & 8,6 & 7,9 & 7,8 & 7,8 & 7,7 & 7,7 & 7,8 \\
OD (mg/L) & 5,4 & 15 & 32,2 & 5,8 & 5,7 & 5,6 & 4,9 & 4,6 & 7,3 & 6,9 & 5,5 & 6,4 \\
CE (mS) & 1,992 & 0,369 & 0,373 & 0,353 & 0,382 & 0,378 & 0,377 & 0,398 & 0,382 & 0,411 & 0,409 & 0,428 \\
Turbidez (NTU) & $\ldots$ & $\ldots$ & $\ldots$ & $\ldots$ & 3,25 & 2,71 & 1,39 & 3,06 & 44,57 & 4,92 & 3,93 & 8 \\
Cd Total (mg/L) & $<0,0005<0,0005<0,0005<0,0005<0,0005<0,0005<0,0005<0,0005<0,0005<0,0005<0,0005<0,0005$ \\
Pb Total (mg/l) & $<0,005$ & $<0,005$ & $<0,005$ & 0,007 & $<0,005$ & $<0,005$ & $<0,005$ & $<0,005$ & $<0,005$ & $<0,005$ & $<0,005$ & 0,01 \\
Coliformes (100mg) & 2200 & 110 & 1100 & 19 & 170 & 1300 & 50 & 110 & $>1600$ & 130 & 280 & 3000 \\
DBO (mg/L) & 4 & $<2$ & 2 & 2 & 2 & 2 & $<2$ & $<2$ & $<2$ & $<2$ & $<2$ & $<2$ \\
DQO (mg/L) & 16 & 5 & 9 & 10 & 7 & 9 & 7 & $<5$ & $<5$ & 10 & 8 & 10 \\
P Total (mg/L P) & 0,04 & $<0,01$ & 0,44 & 0,18 & 0,16 & 0,08 & 0,1 & 0,12 & 0,15 & 0,07 & 0,08 & 0,1 \\
Nitrato (mg N/L) & 17,79 & 0,58 & 0,31 & 0,24 & 0,51 & $<0,01$ & 0,79 & 0,34 & 0,12 & 0,12 & 0,53 & 2,14 \\
Zn Total (mg/L) & 0,97 & 1,29 & 0,13 & 0,17 & 0,89 & 0,09 & 0,09 & 0,15 & 0,04 & 0,06 & 0,1 & 0,15 \\
\hline
\end{tabular}


HADDAD, E.A. e MAGALHÃES JR., A.P. Influência antrópica na qualidade...

\begin{tabular}{|c|c|c|c|c|c|c|c|c|c|c|c|c|}
\hline \multicolumn{13}{|c|}{ SM 05} \\
\hline Data & $18 / \mathrm{abr}$ & $15 / \mathrm{mai}$ & 19/jun & $18 /$ jul & 15/ago & $19 /$ set & $18 /$ out & $20 /$ nov & $11 / \mathrm{dez}$ & $23 /$ jan & $15 /$ fev & $20 /$ mar \\
\hline Horas & $\ldots$ & $12: 00$ & 11:00 & $10: 20$ & 15:00 & $13: 20$ & $15: 30$ & 15:00 & $15: 20$ & $13: 45$ & $16: 30$ & $12: 45$ \\
\hline Vazão $\left(\mathbf{m}^{3} / \mathbf{s}\right)$ & 3,9 & 5,39 & 5,67 & 4,41 & 3,57 & 4,2 & 2,69 & 4,77 & 16,65 & 4,37 & 4,9 & 15,48 \\
\hline $\mathbf{T}\left({ }^{\circ} \mathrm{C}\right)$ & 26,7 & 22,5 & 23,2 & 19,5 & 20,4 & 23,5 & 25,2 & 25,4 & 23,3 & 24,7 & 25,9 & 23,6 \\
\hline pH & 7,1 & 7,5 & 7,3 & 8,5 & 8,7 & 8,6 & 7,9 & 7,8 & 7,8 & 7,7 & 7,5 & 7,7 \\
\hline OD (mg/L) & 4 & 16,6 & 27 & 5,5 & 6,2 & 5,1 & 4,8 & 6,5 & 7,6 & 6,1 & 5,5 & 6,9 \\
\hline $\mathrm{CE}(\mathrm{mS})$ & 0,34 & 0,304 & 0,286 & 0,265 & 0,288 & 0,287 & 0,312 & 0,321 & 0,261 & 0,346 & 0,326 & 0,345 \\
\hline Turbidez (NTU) & $\cdots$ & $\ldots$ & $\ldots$ & 4,57 & 5,11 & 10,65 & 5,1 & 22,9 & 63,06 & 9,24 & 8,46 & 56,31 \\
\hline Cd Total (mg/L) & \multicolumn{12}{|c|}{$<0,0005<0,0005<0,0005<0,0005<0,0005<0,0005<0,0005<0,0005<0,0005<0,0005<0,0005<0,0005$} \\
\hline Pb Total (mg/l) & $<0,005$ & $<0,005$ & $<0,005$ & $<0,005$ & $<0,005$ & $<0,005$ & $<0,005$ & $<0,005$ & $<0,005$ & $<0,005$ & $<0,005$ & 0,027 \\
\hline Coliformes (100mg) & 110 & 230 & 350 & 140 & 110 & 80 & 500 & 220 & $>1600$ & 700 & 220 & 1100 \\
\hline DBO (mg/L) & 2 & $<2$ & 2 & 2 & $<2$ & $<2$ & $<2$ & $<2$ & 2 & 2 & $<2$ & $<2$ \\
\hline DQO (mg/L) & $<5$ & $<5$ & 9 & 7 & 9 & 12 & $<5$ & 5 & 19 & 23 & 9 & 8 \\
\hline P Total (mg/L P) & 0,02 & $<0,01$ & 0,39 & 0,14 & 0,18 & 0,08 & 0,06 & 0,11 & 0,14 & 0,03 & 0,05 & 0,1 \\
\hline Nitrato (mg N/L) & 1,86 & 0,34 & 0,19 & 0,1 & 0,26 & 0,03 & 0,3 & 0,19 & 0,05 & 0,12 & 0,3 & 1,23 \\
\hline Zn Total (mg/L) & 0,92 & 1,11 & 0,09 & 0,13 & 0,073 & 0,12 & 0,09 & 0,14 & 0,12 & 0,06 & 0,09 & 0,19 \\
\hline
\end{tabular}


HADDAD, E.A. e MAGALHÃES JR., A.P. Influência antrópica na qualidade...

\section{APÊNDICE B}

Resultado das análises nas nascentes

\begin{tabular}{l|cc|cc|cc}
\hline & \multicolumn{2}{|c|}{ NV } & \multicolumn{2}{c|}{ LT } & \multicolumn{2}{c}{ QS } \\
\hline \multicolumn{1}{c|}{ Parâmetro } & abril & setembro & abril & setembro & abril & setembro \\
\hline CE (mS) & $3,2 \mu \mathrm{S}$ & $2,8 \mu \mathrm{S}$ & $6,1 \mu \mathrm{S}$ & $6,8 \mu \mathrm{S}$ & $0,338 \mathrm{mS}$ & $0,353 \mathrm{mS}$ \\
Turbidez (NTU) & 1,96 & 1,1 & 2,15 & 6,19 & 1,31 & 1,86 \\
Cd Total (mg/L) & $<0,0005$ & $<0,0005$ & $<0,0005$ & $<0,0005$ & $<0,0005$ & $<0,0005$ \\
Pb Total (mg/l) & $<0,005$ & $<0,005$ & $<0,005$ & $<0,005$ & $<0,005$ & $<0,005$ \\
CT (NMP/100ml) & $<2$ & 20 & $<2$ & $<2$ & 80 & $<2$ \\
DBO (mg/L) & $<2$ & $<2$ & $<2$ & 2 & 3 & 2 \\
DQO (mg/L) & $<5$ & $<5$ & $<5$ & 18 & $<5$ & $<5$ \\
P Total (mg/L P) & 0,03 & 0,03 & 0,02 & 0,08 & 0,27 & 0,05 \\
Nitrato (mg N/L) & 0,03 & 0,13 & 0,04 & 0,02 & 0,3 & 0,02 \\
Zn Total (mg/L) & 0,03 & 0,02 & 0,16 & 0,02 & 0,09 & 0,05 \\
\hline
\end{tabular}

Estatística de parâmetros de qualidade de água na

Estação SF 002A - Calciolândia - 2000 a 2004

\begin{tabular}{rccccc}
\hline & OD & \multicolumn{2}{c}{ Turbidez Colif Fecal* } & P total & Zn Total \\
\hline Unidade & $\mathbf{m g} / \mathbf{L}$ & UNT & NMP/100ml & $\mathbf{m g} / \mathbf{L}$ & $\mathbf{~ m g / L}$ \\
Média Aritmética & 20 & 20 & 20 & 20 & 20 \\
Média Geométrica & 6,58 & 8,56 & 3753,0 & 0,05 & 0,06 \\
Mediana & 6,5 & 5,71 & 1486,85 & 0,04 & 0,05 \\
Mínima. & 5,5 & 1,2 & 1500,0 & 0,0 & 0,06 \\
Máxima & 8,1 & 49,4 & $30.000,0$ & 0,1 & 0,17 \\
Desvio Padrão & 0,63 & 10,64 & 6687,48 & 0,02 & 0,035 \\
Coeficiente de Variação & 0,10 & 1,24 & 1,781 & 0,41 & 0,590 \\
\hline
\end{tabular}

* Coliformes Fecais (o mesmo que Coliformes Termotolerantes).

Fonte: IGAM (2005) 
HADDAD, E.A. e MAGALHÃES JR., A.P. Influência antrópica na qualidade...

Pluviometria (estação Arcos - código 02045010) e média das vazões mensais no rio São Miguel

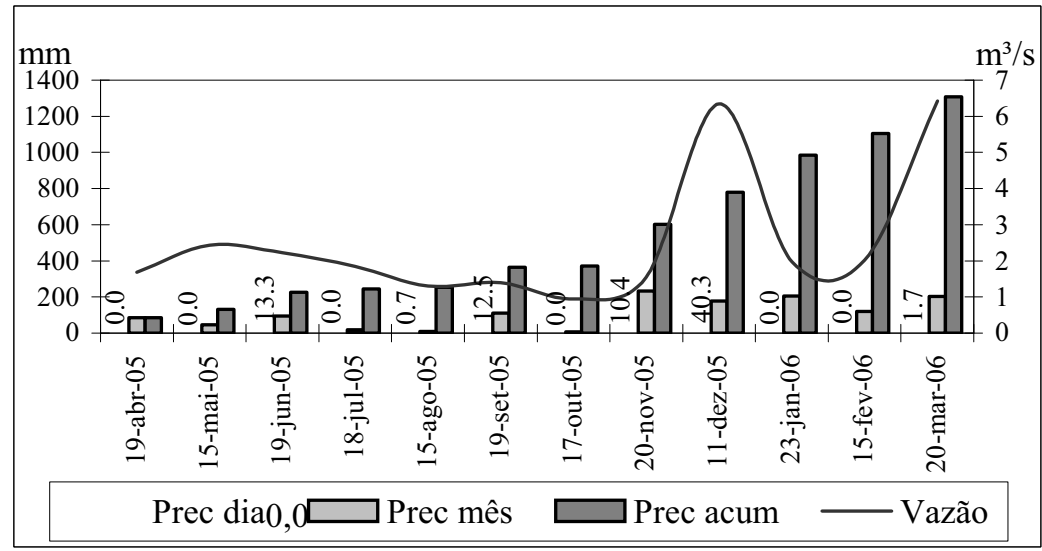

Prec dia - precipitação no dia; Prec mês - precipitação no mês; Prec acum - precipitação acumulada

Fonte: Companhia de Pesquisas e Recursos Minerais - CPRM (no prelo)

Recebido em junho de 2008 Aceito em outubro de 2009 